\title{
El CUENTO COlOMBiano EN EL Boletín Cultural y Bibliográfico: UN RECORRIDO POR LA CRÍTICA Y LAS PUBLICACIONES EN LOS AÑOS 60*
}

\author{
Colombian Short Story in the Boletín \\ Cultural y BibLIOGRÁfico: A Route Across \\ the Critical Reviews and Publications \\ IN THE 60s
}

\footnotetext{
* Artículo derivado de la investigación "1969. Cartografía crítica del cuento en Colombia”, de la Línea de Investigación en Literatura Comparada del Instituto Caro y Cuervo.
}

Cómo citar este artículo: Triana Cuevas, T. C. y Bejarano, J. A. (2022). El cuento colombiano en el Boletín Cultural y Bibliográfico: un recorrido por la crítica y las publicaciones en los años 60. Estudios de Literatura Colombiana 50, pp. 71-86. DOI: https://doi. org/10.17533/udea.elc.n50a04

1 https://orcid.org/0000-0001-8715-4667 tania.triana@caroycuervo.gov.co Instituto Caro y Cuervo, Colombia

2 https://orcid.org/0000-0002-6958-3043 alberto.bejarano@caroycuervo.gov.co Instituto Caro y Cuervo, Colombia

Editores: Andrés Vergara Aguirre, Christian Benavides Martínez

Recibido: 10.08 .2021

Aprobado: 04.10.2021

Publicado: 17.01.2022

Copyright: (02022 Estudios de Literatura Colombiana. Este es un artículo de acceso abierto distribuido bajo los términos de la Licencia Creative Commons AtribuciónNo comercial - Compartir igual 4.0 Internacional

\section{Tania Camila Triana Cuevas, ${ }^{1}$ Julio Alberto Bejarano ${ }^{2}$}

Resumen: En este estudio se lleva a cabo un recorrido por los artículos y los cuentos publicados en el Boletín Cultural y Bibliográfico durante la década de los sesenta, con el fin de observar cuáles eran las posturas críticas de la época sobre el género en Colombia e identificar las tendencias temáticas y formales de los cuentistas con un número considerable de publicaciones durante dicho periodo. De igual manera, el artículo se inscribe en los estudios sobre la circulación literaria que se aproximan a las publicaciones periódicas para reflexionar en torno a otros espacios de diálogo entre autores y críticos.

Palabras claves: cuento; Colombia; Boletín Cultural y Bibliográfico; años 60.

Abstract: In this study, a routing is drawn through the articles and short stories published in the Boletin Cultural y Bibliográfico during the sixties decade, with the aim of observing which were the seasonal critical stances in Colombia about the genre and identifying the thematic and formal tendencies of those narrators with a considerable number of publications during the epoch. Similarly, this article is subscribed to the literary circulation studies that explore the periodical publications in order to reflect upon other spaces of dialogue between authors and critics.

Keywords: Short story; Colombia; Boletín Cultural y Bibliográfico; 60's decade. 
El canon del cuento en Colombia se ha construido alrededor de las historiografías literarias y las antologías que reúnen, por lo general, textos que fueron publicados por sus autores en libros de cuentos. Dentro de este panorama surgen preguntas sobre las clasificaciones que se elaboran en función de los autores, las temáticas, las regiones o incluso las generaciones. La cuestión acerca de la forma en que circulaban los textos, sin embargo, no suele ser el epicentro de la crítica. Por esto, es importante detenerse en la relación del cuento con las publicaciones periódicas y revisar las dinámicas que se configuran a su alrededor.

La circulación literaria, como expone Fabio Akcelrud Durão (2017) en "Circulation as constitutive principle”, dejó de ser una ruta de acceso para convertirse en "a new vector of textual organization to be added to the list of traditional ones, such as time, space, characterization or narrative point of view" (p. 62). Las aproximaciones de este tipo, que también se enfocan en las dinámicas del mercado, contemplan indagaciones que atienden a la manera en que se construyen plataformas que propician la difusión de obras y el diálogo entre autores. En los últimos años múltiples investigaciones - tales como las realizadas en el trabajo con fuentes periódicas por el semillero "Colombia: Tradiciones de la Palabra", coordinado por la profesora e investigadora Ana María Agudelo Ochoa- han evidenciado la importancia que tuvieron los periódicos y las revistas para el género en el país. Debido a que durante mucho tiempo fueron la plataforma de divulgación principal del cuento, diversos trabajos se han dedicado a revisar este tipo de publicaciones.

En el artículo "El cuento en revistas colombianas (1900-1950). Aportes a una historia del género”, Agudelo Ochoa (2018) señala que las revistas, además de ser un "espacio de emergencia, legitimación, formación de un público lector y de un mercado" (p. 15), se destacan porque su estructura dividida en secciones dispone diferentes elementos que "afectan el sentido de los contenidos y la disposición del público lector hacia los mismos” (p. 15). Así, la tendencia de las publicaciones periódicas en el siglo xx de incluir - junto a los ensayos y textos críticos- fragmentos de novelas, poemas y cuentos da cuenta de una apuesta por la escritura creativa por parte de los editores. De igual modo, esta inclinación no solo aseguró la difusión del género, sino que también promovió su producción por parte de los autores más jóvenes, quienes por lo general eran los colaboradores más frecuentes. 
En un estudio anterior, "Hacia una historia del cuento colombiano" (2015), Agudelo Ochoa realiza una cartografía del género en la que revisa y pone en diálogo diversas antologías, revistas y textos críticos. En este balance se exponen los escritores que, a través de su mención continua, consolidaron el canon: Tomás Carrasquilla, Efe Gómez, Adel López Gómez, Hernando Téllez, Pedro Gómez Valderrama, José Félix Fuenmayor, Gabriel García Márquez, Germán Espinosa, Álvaro Cepeda Samudio, Óscar Collazos y, la cuentista más estudiada, Marvel Moreno (Agudelo Ochoa, 2015, p. 162). En la misma línea, Maribel Berrío Moncada, en "El cuento colombiano: análisis de los criterios de selección en las historias y las antologías literarias" (2010), se detiene en los postulados de los críticos y compiladores para identificar las características que se usaron para escoger las obras más destacadas dentro del género.

Su estudio, centrado en el modo en que se legitima la tradición, concluye que el acercamiento se reduce al ámbito tematológico, de modo que "la mayoría no se ocupa de hacer un trabajo de compilación basado exclusivamente en los criterios estéticos de una obra que estén validados por los estudios literarios, dando lugar a un vacío epistémico en la historia del cuento colombiano"(Berrío Moncada, 2010, p. 127). Así mismo, señala que "en las antologías el título funciona como una estrategia para delimitar su objeto de estudio, que da lugar a que los autores se exoneren de argumentar sus criterios de selección para la clasificación de las obras" (p. 126). De este modo, si bien es innegable que existe un consenso alrededor de los escritores más destacados, en estas compilaciones no se explicitan los motivos por los que marcaron un antes y un después en la historia del cuento colombiano.

Otro punto en el que los críticos concuerdan es la importancia que tienen tanto la década de los sesenta como de los setenta para el desarrollo del género. Mientras Luz Mary Giraldo (2017), en “Cuento Colombiano: un género renovado”, advierte que en esta época "los escritores mostraban una arraigada conciencia social” (p. 18), Agudelo Ochoa (2015) apunta que este periodo en las antologías se destaca debido a que se da "un movimiento de ruptura y renovación narrativa que se evidencia en el paso de los temas locales a temas universales" (p. 153). Surgen, entonces, preguntas sobre cómo estos cambios — que dieron apertura al cuento moderno en el país- se configuraron en las publicaciones periódicas, en torno a la participación de los autores canonizados en estos espacios y acerca de las producciones olvidadas que no se encuentran en un libro de cuentos. 
Una de las revistas menos citadas pero de mayor importancia debido a su trayectoria y a la calidad de sus colaboradores es la publicación oficial de la Biblioteca Luis Ángel Arango, el Boletin Cultural y Bibliográfico. Como indica su página web, circuló por primera vez en 1958 y desde entonces se ha distinguido por cumplir la función de rescate, investigación, análisis y difusión del patrimonio cultural. A lo largo de sus números ha consignado los cambios que han experimentado diversas disciplinas entre las que se destaca la literatura. Dado que en sus cuatro etapas ha acogido ensayos críticos y múltiples textos inéditos, es una fuente que favorece la observación del recorrido y el impacto que el género ha tenido en Colombia. ${ }^{1}$

\section{Un panorama breve por la trayectoria del cuento en el Boletín Cultural y}

\section{Bibliográfico}

Antes de comenzar la indagación que corresponde a los textos que se publicaron en la década de los sesenta, es importante realizar una revisión panorámica del papel que ha tenido el género en la revista a lo largo del tiempo. Actualmente el Boletín Cultural y Bibliográfico cuenta con cuatro secciones regulares: "Artículos", "Reseñas", "Varia" y "Rescates, réplicas y contrarréplicas". ${ }^{2}$ En el archivo virtual las entradas del cuento se localizan en las tres primeras y se registra un total de 119 notas publicadas entre el año 1961 y el 2021: 71 entradas en "Artículos", 33 en "Reseñas" y 15 en "Varia". Si bien la división propuesta por la revista permite ubicar el material, la variedad del mismo desborda los apartados de forma, por lo que resulta indispensable definir otros criterios de discriminación.

Así, durante el rastreo realizado se efectuó la siguiente subdivisión para atender a la particularidad de los contenidos. En los setenta y un artículos sobre el género se hallaron sesenta cuentos, nueve textos de crítica literaria, un rescate y un índice de obras representativas con sus respectivos autores. En las treinta y tres reseñas se comentaron veinte libros de cuentos, once antologías, un libro de ensayos y también se dedicó un espacio para presentar los resultados de un concurso de cuento. Finalmente, las quince entradas en "Varia" corresponden a la difusión de concursos a nivel nacional e internacional (Figura 1).

1

Si bien aún tiene un espacio abierto para los textos creativos, actualmente solo publica poesía. Una tendencia que siguen otras publicaciones como la revista literaria Ulrika de Bogotá.

Otras, tales como "Poemas", "Extras web”, "Ilustraciones” “ Otras secciones”, son incluidas en algunos números. 
Fuente: elaboración propia.

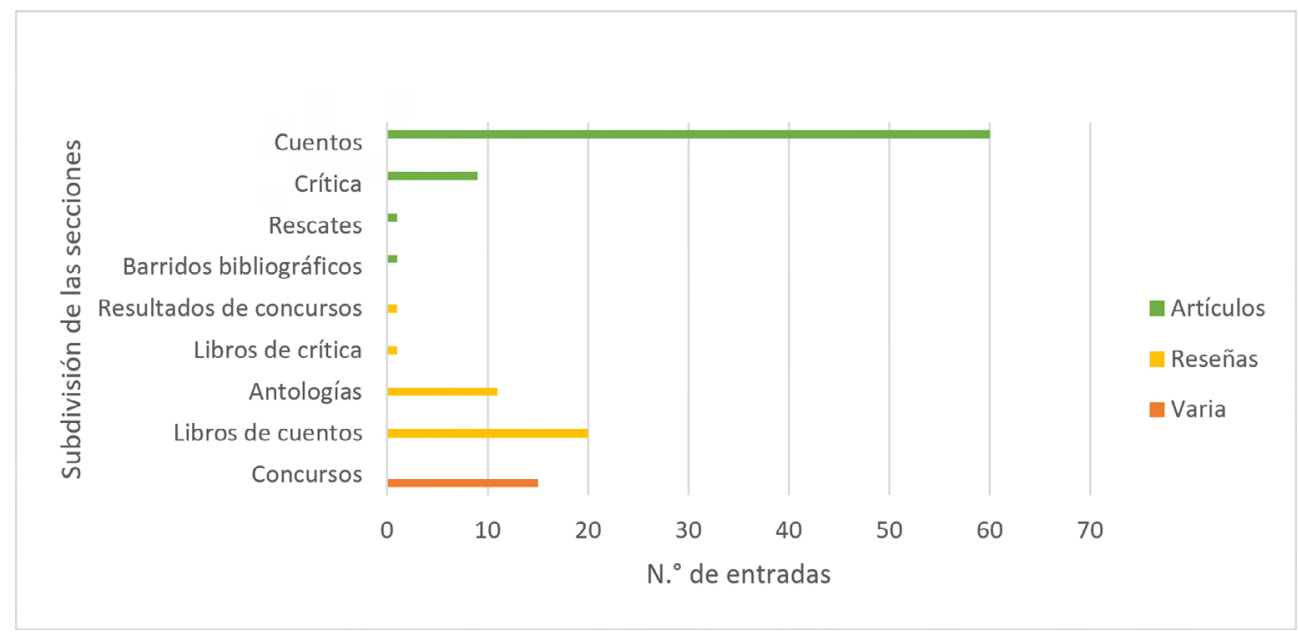

Figura 1. Cuentos y otras entradas del género publicadas en el Boletín Cultural y Bibliográfico.

El mayor número de publicaciones data de los años 60. En esta década salieron a la luz sesenta y dos textos que, además de abarcar casi la totalidad de la crítica del catálogo, incluyen cincuenta y nueve cuentos. En comparación, se registran seis entradas en la década de los 70, nueve en la de los 80, doce en la de los 90, trece en la de los 2000 y, finalmente, diez y siete del 2010 al 2021. De igual manera, el periodo de los 60 se destaca debido a colaboradores notables — como Manuel Zapata Olivella, Germán Espinosa, Adel López Gómez y José Pubén- que aportaron de manera constante.

\section{El lugar del cuento: la crítica de los 60 en el Boletín Cultural y Bibliográfico}

La reducida cantidad de reflexiones sobre el género, en comparación con el vasto número de las producciones creativas, evidencia un interés mayor en este por parte de los escritores que de los críticos, y abre una cuestión en torno al lugar que ocupó el cuento en el campo literario en esta década. En los 60, tres artículos del Boletín se destacan por su interés en el cuento: "El cuento en Colombia"(1965) de Eduardo Pachón Padi1la, "Fichas sin revisar: Sobre la novela y el cuento" (1967) de Germán Vargas y "Breve noticia sobre el cuento en Colombia” (1968) de Néstor Madrid Malo. La definición del género que propone Pachón Padilla — uno de los pocos autores que se ha dedicado al estudio del cuento de manera sistemática - se concentra en el aspecto temático y se detiene en los dos elementos que, según él, caracterizan las obras del siglo xx: 
El uno se concreta a inspeccionar los diferentes factores objetivos, tales como el medio, el clima y el paisaje, que, con omnipotencia, dominan al hombre americano, el cual se encuentra trágicamente supeditado por un escenario agreste, de naturaleza múltiple, especificada en lo vernáculo, supersticioso, fatal, etcétera. El otro se dirige a lo netamente subjetivo, originado por diversas circunstancias inherentes al hombre mismo, dependientes de estados relacionados con su cultura, carácter, complejos y modos de subsistencia (Pachón Padilla, 1965, p. 183).

El enfoque telúrico y la perspectiva psicológica se postulan como las bases de la producción colombiana. Para el compilador de los dos tomos de Antología del cuento colombiano (1985) esto se debe a la herencia de los cuadros de costumbres del siglo XIX y a la influencia de la literatura europea y norteamericana.

Vargas, en cambio, desvía la atención de la discusión a la pregunta sobre el oficio del escritor. Su preocupación lo lleva a unir al cuento y a la novela bajo una misma categoría que, al final, impide observar las singularidades de cada uno. La narrativa, entonces, carece de importancia y se suma al problema de "la habitual pereza de nuestros escritores que prefieren seguir el llamado de la política o el periodismo fácil de notas" (Vargas, 1967a, p. 117). El integrante del denominado Grupo de Barranquilla extiende su reparo en el artículo "Vargas Llosa y la vocación literaria" (1967) — también publicado en el Boletín - donde afirma que la verdadera dificultad que afrontan las letras latinoamericanas, más allá de las cuestiones de forma y fondo, radica en la falta de seriedad con la que se toma la labor (Vargas, 1967b, p. 159).

Por último, Madrid Malo recurre a las nociones comunes existentes del género para ir profundizando paulatinamente en meditaciones más complejas sobre los rasgos que lo definen. De forma que se remite a la acepción que brinda el Diccionario de la Literatura Española:

Es el cuento [...] una de las manifestaciones en que más difícil resulta lograr la perfección, ya que su técnica exige del autor una capacidad de síntesis combinada con una serie de calidades estéticas que deja en el ánimo del lector la impresión de que el relato cumple una verdadera misión artística (Madrid Malo, 1968, pp. 108-109).

La brevedad y el efecto con los que generalmente se asocian estas narraciones sirven de punto de partida para el análisis del ensayista. Sin embargo, aun cuando parecen elementos concretos, la falta de detalle en esta "serie de calidades estéticas" genera una ambigüedad que, lejos de facilitar claridades, provoca desconciertos. Por esta razón, y a causa de que se ubica en un espacio fronterizo junto a la novela y el relato, Madrid Malo le adjudica el calificativo de "un esquivo género". 
Además, se suma el "mal endémico" de la cuentística colombiana que —en línea con lo planteado por Germán Vargas— se observa en "la discontinuidad de la obra" (Madrid Malo, 1968, p. 116). Si bien aquí apenas se menciona, esta apreciación abre un interrogante en torno a la manera en que los escritores conciben la labor del cuentista. En el artículo "El peligro de las antologías", Policarpo Varón (1967) sugiere una posible respuesta: "Ha dicho György Lukács que el cuento es un precursor o un sucesor de la novela (en el sentido de que se da o como iniciación o como culminación de una etapa de producción novelística)" (p. 807). Y, más adelante, continúa:

En el desarrollo de la literatura latinoamericana [...] vemos que la mayoría de nuestros novelistas se han iniciado como cuentistas; han publicado para empezar un libro de cuentos [...]. Aunque va convirtiéndose en un peligro para el desarrollo de una literatura más ambiciosa; una literatura que no puede quedarse dentro de lo menor, lo ligero (p. 807).

El género se perfila, principalmente, como una escuela en la que se pule la escritura mientras se alcanza la "mayoría de edad". Componer asiduamente obras de esta naturaleza, bajo la lógica de Varón, solo entorpece la actividad del prosista que aspira - $\mathrm{O}$ que debería aspirar - a la elaboración de una obra extensa. Este fenómeno se dio en el ámbito latinoamericano y llevó a que, durante largo tiempo, el cuento se considerara un camino o un laboratorio hacia futuras novelas, como se mencionó anteriormente.

De este modo, el cuento adquiere en la época el calificativo de género menor, una idea que terminó por relegarlo a menciones efímeras que funcionaban como antesala a la introducción de otras obras o como datos curiosos en las biografías de los autores. Madrid Malo (1968), quien difiere de este parecer, rescata los avances formales que el cuento comenzaba a manifestar en Colombia en los años 60:

En un breve movimiento ascensional y depurador nuestra narración breve deja de ser la descripción, el relato de algo, para construirse en la vivencia, en la expresión de algo, que el escritor no logra ya por medios descriptivos sino a través de módulos expresivos. De contar una realidad de vida, se pasa a narrar aquella "realidad del espíritu" (p. iı).

El paisaje, antes el único actor, entabla un diálogo con los sujetos que lo habitan. Por medio de la perspectiva interior de los personajes, las historias pasan de ser simples anécdotas a transformarse en experiencias nuevas que se fundan en el lenguaje.

Aun cuando las aproximaciones a la definición del cuento por parte de los críticos abarcan diferentes aspectos, todos coinciden en las etapas de su desarrollo en el país. Sus antecedentes datan del costumbrismo que se caracterizó por "su interés 
demasiado doméstico" (Vargas, 1967a, p. 118) y "sus fines exclusivamente didácticos y moralizantes" (Madrid Malo, 1968, p. 109). La favorable acogida que tuvo en el momento es atribuida por Pachón Padilla (1965) a "la facilidad de su divulgación por medio del periódico [...] [y a su] fórmula especial que daba la impresión de que el lector veía lo que estaba leyendo" (p. 108). De sus exponentes, Vargas destaca a José María Vergara y Vergara debido a que sus textos dan cuenta del exagerado localismo que impidió la difusión de los cuadros de costumbres fuera del ámbito escolar y regional, mientras que Pachón Padilla distingue a aquellos autores que, como Soledad Acosta de Samper y José María Rivas Groot, lograron capturar su presente en valiosos documentos históricos disponibles en el semanario El Mosaico.

Con la llegada del realismo se abandona la pretensión de objetividad, aunque el espacio sigue siendo un elemento central. La escuela antioqueña, como la llamó el ensayista y antologista, mezcló "lo primitivo, geográfico, climatológico, mágico, sobrenatural y demás, con lo señaladamente social, histórico, político, económico, etnográfico, etcétera” (Pachón Padilla, 1965, p. 184). Obras como "E1 ánima sola” (1898) y "Rogelio" (1926) de Tomás Carrasquilla, “Que pase el Aserrador” (1916) de Jesús del Corral y "Guayabo negro" (1923) de Francisco Gómez Escobar —más conocido como Efe Gómez-, a pesar de que mantienen la inclinación por lo vernáculo, introducen tradiciones populares, asuntos fantásticos y recursos simbólicos que renuevan el estilo literario. No obstante, en los últimos años esta perspectiva ha adquirido matices que han permitido repensar el costumbrismo y abordarlo desde otros ángulos. ${ }^{3}$

Otro de los críticos que sitúa el origen del cuento colombiano en Antioquia es Madrid Malo (1968), quien estima que el entorno, además de propiciar que las narraciones exploren "la conciencia del hombre con sus problemas y con sus dramas universales" (p. 111) en escenarios concretos, incide considerablemente en las dinámicas de producción. El movimiento de las publicaciones periódicas, la pronta o tardía llegada de determinados movimientos y el diálogo entre los escritores da cuenta de las prácticas que varían de región en región. Por esta razón, trazar un recorrido del género a través de sectores territoriales favoreció el estudio de Madrid Malo, puesto que le posibilitó identificar algunas de las causas detrás de los cambios que experimentó el cuento.

Tal es el caso del estudio "Tomás Carrasquilla y los críticos colombianos del siglo xx" (2008) de Pablo Montoya. 
No obstante, también se valió del criterio temporal e hizo uso de la división por décadas para ubicar coyunturas significativas. A mediados de los años 20, por ejemplo, establece el paso definitivo del relato al cuento moderno con la consolidación del componente psicológico e interior visible en las obras de José Restrepo Jaramillo y Eduardo Arias Suárez, dos autores prácticamente olvidados. Finalmente, antes de revisar el estado actual, se detiene en los años 40 para señalar "un fenómeno que habrá de tener hondas repercusiones, tanto en el cuento como en la novela nacionales: la aparición de los autores de la costa atlántica, ancha región del país que hasta entonces no habrá contado seriamente en nuestra narrativa” (Madrid Malo, 1968, p. 116). García Márquez instaurará en este periodo "medios novedosos y de una selectividad temática poco común” (p. 117) que luego serán acogidos por Álvaro Cepeda Samudio y Eduardo Arango Piñeros. Sin embargo, no se llega a precisar cuáles son dichas transformaciones.

Tanto Pachón Padilla como Madrid Malo, al llegar a la década del 50, dejan de concentrarse en el género para enfocarse en los tópicos comunes de la literatura que les era contemporánea. Se destaca la continuidad del interés por la relación entre el sujeto y su contexto, tal como se observa en los cuentos con contenidos sociopolíticos de Jesús Zárate Moreno, Judith Porto de González, Tomás Vargas Osorio, Carlos Arturo Truque, Octavio Amórtegui y Antonio García. ${ }^{4}$ El paisaje en este panorama, como expone Varón (1967), pese a que integra aspectos metropolitanos, no acaba de alejarse de los elementos agrestes, de manera que "no se puede hablar de narrativa rural y narrativa urbana, ni que se ha pasado de la una a la otra" (p. 809). La simultaneidad de corrientes aparentemente dispares se observa, de igual modo, en la coexistencia de argumentos que seguían relatando la violencia y otros que, ${ }^{5}$ por el contrario, se alejaban de lo local para acercarse a lo que Pachón Padilla denominó "lo extraño y exótico". ${ }^{6}$

Los años 60 se presentan, entonces, como la continuación de una época de movimiento en la que, debido a la multiplicidad de intereses y a la tensión entre las tendencias, definir los nuevos rumbos del género se tornó cada vez más complicado. Así, para concluir sus textos, los críticos optaron por mencionar autores y títulos

4 Reconocido por el cuento “Colombia S.A.” (1934) que, por su carácter crítico, se convirtió en un referente.

5 Como "Sangre en los Jazmines" (1950) de Hernando Téllez y "El círculo” (1959) de Elisa Mújica.

6 Caso de "La grieta” (1941) de Jorge Zalamea, "El regreso" (1947) de Arturo Laguado y "A dónde va Mr. Smith” (1955) de Arango Piñeres. 
notables que, junto a otros artículos como "Síntesis de la literatura colombiana" de Gertrude Hudson (1966), proponen un canon contemporáneo. En estos catálogos se distingue a Manuel Mejía Vallejo — declarado por Madrid Malo como el primer cuentista nacional - por la forma en que en sus libros Tiempo de sequía (1957) y Ciclo cerrado (1963) se manifiestan las angustias y las esperanzas del ser humano "con seguridad expresiva y rasgos bien delineados” (Madrid Malo, 1968, p. 119). Así mismo, se resalta la puesta en escena de la vida costera que José Francisco Socarrás realiza en Viento del trópico (1961), la cual, según la reseña de Javier Arias Ramírez (1961), no pierde la densidad psicológica gracias al uso de "nombres y conflictos [que] tienen raíces de carne y hueso" (p. 59). También se alude, por un lado, a la prosa de Mario Franco Ruiz en Los hijos de Job (1960) por la ruptura que marca al desprenderse de la realidad externa, y, por otro, a la incursión de Manuel Zapata Olivella en el género con Cuentos de muerte y libertad (1961) y ¿Quién le dio el fusil a Oswald? (1967). Finalmente, se nombran algunas obras de la nueva generación de cuentistas colombianos entre las que se encuentran Cuando termine la lluvia (1963) de Antonio Montaña, Sexo y saxofón de Gonzalo Arango, Las distancias doradas (1964) de Fanny Buitrago y El verano también moja las espadas (1966) de Óscar Collazos.

A partir de estos recorridos y análisis surgen varias consideraciones y reflexiones que se dieron en torno al género durante este periodo. En primer lugar, sobresale el hecho de que se consideró el "sector de la literatura colombiana [que] ha sido objeto de menos estudio" (Madrid Malo, 1968, p. 108), aun cuando fue "el género que más prosperó en Latinoamérica” (Varón, 1967, p. 108). En segundo lugar, se advierte que en las selecciones de los críticos únicamente se tienen en cuenta los textos que aparecen en libros de cuentos, de manera que se excluyen todos aquellos que circulan en otros espacios como las revistas o los concursos de cuento. ${ }^{7}$

Este hecho conduce a la tercera cuestión: ¿qué determina que un escritor sea un cuentista? Madrid Malo (1968), el único que repara en el asunto, se pregunta "si es cuentista, o poeta, novelista o dramaturgo, quien posee una afirmada obra en ese terreno, o [quien es] el autor de una sola obra” (p. 115). La pregunta, planteada estrictamente en términos de extensión, es solucionada por el crítico por medio de 
la división tradicional de los géneros literarios: "lo que hace a la novela y el drama, puede muy bien suceder esto último. Pero creemos que, en el terreno del cuento y la poesía, no basta con haber escrito un poema o una narración breve para ser ya un cuentista o un poeta" (p. 115). Se privilegia, en este caso, el volumen de la trayectoria a la calidad del texto.

La proximidad propuesta por Madrid Malo entre la poesía y el cuento da paso a la cuarta y última consideración: las fronteras del género. A pesar de que este se vincula — como se señaló anteriormente- a la novela por su función formativa, la brevedad del poema abre otras posibilidades de diálogo. En la nota "Breve noticia sobre el cuento en Colombia” se recuperan las palabras del crítico de arte y profesor de humanidades Javier Arango Ferrer:

El poema y el cuento serán eternamente el comprimido de ensueño que narcotice un poco la realidad de la vida. Pero hasta en el cuento cabe el poema, lo mismo que la farsa y la tragedia, y me atrevo a decir que la pintura y la escultura y hasta la misma música. Así, me parece un molde en el que caben todas las posibilidades artísticas. Comparo el cuento a un soneto y el poeta que en su soneto no tenga campo para expresar todo un estado de alarma es porque nunca ha sido poeta (Madrid Malo, 1967, p. I13).

La tensión entre la fugacidad y la profundidad junto a la capacidad de contener imágenes e historias en pocas palabras plantean otro paradigma desde el cual pensar el cuento en relación con otros géneros.

\section{Cuentos de los 60: las publicaciones en el Boletín Cultural y Bibliográfico}

A diferencia de la escasa aparición de ensayos críticos, la cantidad de cuentos publicados en el Boletín revela que durante esa época la revista se consolidó como un espacio de difusión del género. En sus páginas se encuentran autores reconocidos como Clemente Airó, director de Espiral. Revista mensual de artes y letras, y otros menos conocidos como el tolimense Hugo Ruiz o el fotógrafo Gabriel Carvajal. En la década de los 60 hubo un total de diecinueve cuentistas entre los que se destacan Adel López Gómez, Carlos Delgado Nieto, José Pubén y Policarpo Varón, por el número de sus entradas. ${ }^{8}$

López Gómez, oriundo de Armenia, publicó a lo largo de su vida veintiún libros en los que incursionó también en la novela y la poesía. Su basta prosa, "donde tanto

En orden respectivo publicaron catorce, ocho, seis y cinco cuentos. 
hay del paisaje y del hombre colombianos" (Madrid Malo, 1968, p. 114), es catalogada como costumbrista y, debido a la simpleza de sus tramas, "se ha dicho que sus cuentos son más bien relatos" (p. 114). En su catálogo del Boletín sobresalen temas como las dinámicas sociales rurales — presentadas en "El hombre que preparaba su propio café" (1966) —, las relaciones de maritales — puestas en escena en "La casa" (1967) — y La Violencia —abordada en "Caminos de sangre" (1968)—. No obstante, si bien su perspectiva integra las "buenas costumbres" de la época, el autor se distancia de los cuadros del xIX, ya que prescinde del elemento aleccionador que los distingue.

En términos formales, la división por escenas y la construcción de historias a partir de diálogos dan cuenta del componente teatral que permea sus cuentos. En "Allá en el golfo" (1969) y "La escondida senda"(1967) la acción sucede en las conversaciones de los personajes que, a medida que transcurre el tiempo, tejen la estructura tradicional de inicio, nudo y desenlace. Otros, en cambio, como "Sed" (1968), "El tesoro" (1968) y "La carta" (1969) se acercan más a las tendencias latinoamericanas de los 60 puesto que, además de jugar con el giro del argumento, exploran lo fantástico y lo absurdo.

De modo similar, Delgado Nieto se inscribe en la línea de escritores para los que la presencia de la realidad exterior es fundamental. Sin embargo, al dejar de concebirlo como un conjunto estático de decorados, el periodista y ensayista procedente de Mompox consigue que se ponga en movimiento por medio de los desplazamientos de los personajes. En narraciones como "La trinidad" (1966) y "El infarto" (1967), el espacio cobra profundidad y la pretensión fotográfica es sustituida por una aproximación a lo sensorial en la que se introduce el calor de la costa y el alboroto de la ciudad.

Otra de las innovaciones que Delgado Nieto lleva a cabo se observa en "Cobardías" (1967) y “Teoría femenina” (1968), donde las historias se desvían poco a poco de su aparente centro y adquieren miradas contemplativas que transforman el curso de los cuentos. En "Juego de lápices" (1965) y "Laura busca su alma" (1968) se toma distancia por completo de la linealidad secuencial. Ambos cuentos se construyen de dos relatos en los que el primero parece una excusa para develar el segundo hasta que, en los párrafos finales, el asunto original vuelve a aparecer para darle un cierre a la trama.

A diferencia de los autores anteriores, José Pubén se inclina por el uso de la tercera persona, aunque no desecha por completo la subjetividad que brinda la primera persona. En “iQue se manchen las flores!” (1966) y “La mecedora” (1966), por ejem- 
plo, opta por alternar los dos tipos de narraciones, lo que le permite incluir múltiples ópticas de un mismo acontecimiento. Su estilo, más condensado y menos descriptivo, se separa del interés por la radiografía social y se concentra en situaciones puntuales y fugaces. El tolimense incorpora pasajes en los que, a través de la contemplación y meditación de las tragedias, los personajes — como el niño llevado por la corriente del río desbocado en "Agua rota" (1967) — prolongan los instantes en los que su sosiego es interrumpido abruptamente. La suspensión del tiempo en el lenguaje llega aún más lejos en "Monte de fuego y oscuridad" (1967), donde la aparición de versos detiene la acción para atender a lo que vive el soldado que perdió a su compañero.

Por su parte, Policarpo Varón abarca diversos temas en sus entradas. ${ }^{9}$ El paso del tiempo que azota a las poblaciones marginales y a sus habitantes, por ejemplo, es el motivo central de "Un hombre sin fe" (1968) y "El último viernes de una guerra" (1969). Desde la perspectiva de aquellos que vivieron el periodo más álgido de las tensiones políticas, se da cuenta del olvido que corroe lentamente los estandartes de héroes y las creencias en la patria. En otros cuentos como "Jonás" (1968) y "Un ladrido al otro de lado de las colinas" (1968), utiliza la oralidad para narrar anécdotas comunes que tejen misterios ordinarios como el secreto de un ahogado y la pérdida de un perro. Por último, en "Los mellizos" (1967) se acerca al absurdo por medio del juego del doble.

Antes de finalizar este recorrido, es importante mencionar que durante la década de los 60 otros textos de diversos autores exploraron las tensiones, temáticas e intereses que los críticos de la época asociaron a la producción del cuento moderno en el país. Mientras que obras como "Venancio el Rojo" (1968) de Mario Rivero siguieron narrando episodios vinculados con la Violencia y otras como "El Galeón Sumergido" (1962) de Manuel Zapata Olivella y "La vida comienza a las 6 p.m.”(1967) de Clemente Airó continuaron trazando la relación de los personajes con el espacio, cuentos tales como "El bisturí de la belleza" (1962) de Jaime Ibáñez, "Objetos perdidos”(1966) de Gabriel Carvajal, "Una esquela para María Victoria”(1967) y "Alguien viene de noche a casa" (1968) de Hugo Ruiz se inclinaron por explorar lo fantástico y el componente psicológico de los protagonistas. Así, la participación tanto de los cuatro colaboradores principales como de los demás escritores —que provenían de 9 Quien se trasladó de Ibagué a Bogotá donde, al igual que la mayoría de los colaboradores del Boletín de la
época, escribió gran parte de su obra. 
diferentes regiones del país - dan cuenta, por un lado, del movimiento que el género tuvo durante este periodo y, por otro, de la relevancia de la revista en el país.

\section{El Boletin Cultural y Bibliográfico, entre la crítica y la divulgación: conside- raciones finales}

Este recorrido por el Boletín Cultural y Bibliográfico se enmarca en los estudios que pretenden rescatar los textos de la transitoriedad que es inherente a las publicaciones periódicas donde son presentadas. En Las revistas literarias: un estudio introductorio, Rafael Osuna (2004) señala que "una revista no se hace para el futuro, sino para el presente" ( $\mathrm{p} 22$ ) y advierte que "Esto no significa que sus textos sean provisionales ni que no busquen el esmero. Significa sólo que la revista pretende ofrecer el testimonio de un instante y por ello se muestran tan fértiles para la constatación de las preocupaciones literarias de un momento dado" (p. 22).

La diversidad de las entradas junto a la variedad de los colaboradores, en esta medida, son por sí solos un indicador de la producción del género y de la manera en que se configuraron sus estudios. No obstante, aun cuando las reflexiones de Pachón Padilla, Vargas y Madrid Malo parten de la división regional y se concentran en las divisiones tematológicas, los ensayistas brindan criterios claros que configuran una definición del género y señalan las tendencias que marcan la apertura del cuento moderno. En primer lugar, se identifica la distinción entre el relato y el cuento, entre la anécdota y la construcción narrativa. En segundo lugar, se observa la predilección de los escritores colombianos por lo local, una tendencia que se remonta a los antecedentes del género y que - pese a dejar de ser un eje central — siguió siendo un asunto recurrente, como se constata en las obras referenciadas. Finalmente, en tercer lugar, se señala y se comenta, aunque brevemente, la relación del cuento con la novela y la poesía.

Esta época se presenta no solo como un momento de consolidación de unas nociones y unas consideraciones sobre el cuento, sino que también representa una transición. Los 60 son una bisagra que, por un lado, realiza una apertura a temáticas novedosas - como lo urbano, lo fantástico y lo absurdo-y que, por otro, favorece la exploración de nuevos lenguajes y la experimentación de otras estructuras (Giraldo, 2017, p. 17). El gran número de cuentos, además de advertir la transformación de la narrativa, sugiere que existe un vínculo entre la cantidad de la producción y el reconocimiento del cuentista. Al cotejar a los colaboradores asiduos del Boletín con los autores inclui- 
dos en antologíasy los mencionados en estudios críticos — tales como el de Agudelo Ochoa- ${ }^{10}$ se evidencia la estrecha relación que tenía la circulación de las obras con la selección de las compilaciones.

Pese a que el acercamiento a este archivo fue motivado por la búsqueda de cuentos y escritores olvidados, al final expuso los asuntos principales del debate en torno al cuento durante el periodo de mayor aparición en la revista y puso a dialogar algunos de los textos inéditos publicados. Después de esta primera aproximación, que partió de una delimitación temporal, resulta indispensable pasar de la clasificación inicial de las 118 entradas sobre el cuento en el Boletin Cultural y Bibliográfico a la indagación total del material.

El recorrido planteado, que reúne discusiones teóricas y propuestas literarias, abre preguntas acerca de las dinámicas editoriales — tales como curaduría, publicación, circulación y recepción- que trascienden el interés que despertó el Boletín en críticos y escritores. No obstante, es importante destacar que los trabajos sobre la revista son nulos, aun cuando es un referente de la cultura y la literatura. Por consiguiente, la aproximación a su archivo brinda la oportunidad de generar nuevas discusiones sobre las obras, los autores, las temáticas, los estilos y las formas literarias que, a su vez, permiten repensar el canon colombiano. Igualmente, el hallazgo de la periodicidad del género en la década de los 60 soporta las afirmaciones de los investigadores que sitúan en este periodo el punto álgido de la producción del género en Colombia.

Para cerrar vale la pena detenerse en dos cuestiones que la presente investigación formula. La primera se configura alrededor de la etiqueta del "cuentista" y las condiciones que promueven o aminoran su producción, y la segunda se refiere a las condiciones que excluyeron de las antologías y de los libros de cuentos las obras que se publicaron únicamente en revistas de las antologías. Estas reflexiones, apenas enunciadas, invitan a continuar indagando más allá de los libros publicados y a atender otros archivos — como publicaciones periódicas y concursos- para abordar críticamente más espacios de difusión del género. El estudio de los archivos literarios, en particular de las publicaciones periódicas, brinda nuevas posibilidades para indagar las dinámicas a través de otros parámetros que enriquecen y amplían las propuestas de las antologías.

\footnotetext{
10 Por mencionar algunas: Diez narradores colombianos (1977) de Óscar Collazos, Veinte ante el milenio: cuento colombiano del siglo XX (1994) de Eduardo García, Colección de cuentos colombianos (2002) de Harold Kremer y Cuentos y relatos de la literatura colombiana (2005) de Luz Mary Giraldo.
} 


\section{Referencias bibliográficas}

Agudelo Ochoa, A. M. (2015). Hacia una historia del cuento colombiano. Inti: Revista de literatura hispánica 81, pp. 147-169. Recuperado de https://digitalcommons.providence.edu/inti/vol1/iss81/6 [25.10.2021].

Agudelo Ochoa, A. M. (2018). Presentación. El cuento en revistas literarias colombianas (1900-1951). Aportes a una historia del género. Anales De Literatura Hispanoamericana 47, pp. 13-16, DOI: https://doi.org/10.5209/ALHI.62724

Akcelrud Durão, F. (2017). Circulation as constitutive principle. En J. L. Jobim (Ed.). Literary and Cultural Circulation (pp. 55-72). Oxford: Peter Lang Verlag.

Arias Ramírez, J. (1961). El cuento en Colombia. Viento de Trópico. Boletín Cultural y Bibliográfico 4 (1), pp. 58-59. Recuperado de https://publicaciones.banrepcultural.org/index.php/boletin cultu-

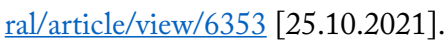

Berrío Moncada, M. (2010). El cuento colombiano: análisis de los criterios de selección en las historias y las antologías literarias. Estudios de Literatura Colombiana 26,pp.109-130. Recuperado de https:// revistas.udea.edu.co/index.php/elc/article/view/9872 [25.10.2021].

Giraldo, L. M. (2017). Cuento colombiano: un género renovado. Folios 15, pp. 13-21.

Madrid Malo, N. (1968). Breve noticia sobre el cuento en Colombia. Boletín Cultural y Bibliográfico 11 (10), pp. 108-120. Recuperado de https://publicaciones.banrepcultural.org/index.php/boletin cultural/article/view/3951 [25.10.2021].

Osuna, R. (2004). Las revistas literarias: un estudio introductorio. Cádiz: Universidad, Servicio de Publicaciones.

Pachón Padilla, E. (1965). El cuento en Colombia. Boletín Cultural y Bibliográfico 8 (2), pp. 181-186. Recuperado de https://publicaciones.banrepcultural.org/index.php/boletin cultural/article/ view/5197 [25.10.2021].

Vargas, G. (1967a). Fichas sin revisar: Sobre la novela y el cuento en Colombia. Boletín Cultural y Bibliográfico, 10 (10), pp. 117-120. Recuperado de https://publicaciones.banrepcultural.org/index.php/ boletin cultural/article/view/4179 [25.10.2021].

Vargas, G. (1967b). Vargas Llosa y la vocación literaria. Boletin Cultural y Bibliográfico 10 (12), pp. 158160. Recuperado de https://publicaciones.banrepcultural.org/index.php/boletin cultural/article/ view/4100 [25.10.2021].

Varón, P. (1967). El peligro de las antologías. Boletín Cultural y Bibliográfico 10 (4), pp. 807-809. Recuperado de https://publicaciones.banrepcultural.org/index.php/boletin_cultural/article/view/4398 [25.10.2021]. 